\title{
Erratum to: Iridoid and phenylethanoid glycoside production and phenotypical changes in plants regenerated from hairy roots of Rehmannia glutinosa Libosch.
}

Ewelina Piątczak $^{1}$ - Lukasz Kuźma ${ }^{1} \cdot$ Ewa Skała $^{1}$ - Marta Żebrowska ${ }^{2}$.

Ewa Balcerczak $^{2} \cdot$ Halina Wysokińska ${ }^{1}$

Published online: 17 June 2015

(C) Springer Science+Business Media Dordrecht 2015

\section{Erratum to: Plant Cell Tiss Organ Cult}

DOI 10.1007/s11240-015-0727-1

Some of the top row headings were mixed up in Table 3 of the original publication. The original publication has been updated to correct those errors.

The online version of the original article can be found under doi:10.1007/s11240-015-0727-1.

Ewelina Piątczak

ewelina.piatczak@umed.lodz.pl

1 Department of Biology and Pharmaceutical Botany, Medical University of Łódź, Muszyńskiego 1, 90-151 Lodz, Poland

2 Laboratory of Molecular Diagnostic and Pharmacogenomics, Department of Pharmaceutical Biochemistry and Molecular Diagnostic, Medical University of Łódź, Muszyńskiego 1, 90-151 Lodz, Poland 